\title{
IS PLAQUE REMOVAL EFFICACY OF TOOTHBRUSH RELATED TO BRISTLE FLARING? A 3-MONTH PROSPECTIVE PARALLEL EXPERIMENTAL STUDY
}

\author{
Pradeep S. Tangade ${ }^{1}$, Aasim Farooq Shah ${ }^{1}$, Ravishankar TL ${ }^{1}$, Amit Tirth, \\ Sumit Pal ${ }^{1}$
}

\begin{abstract}
BACKGROUND: Toothbrushes are over-the-counter products; therefore, no special instruction is given to users when they purchase. There are scarce published studies that have investigated about how often toothbrushes should be replaced. Thus, this study aimed to verify the impact of the Progressive Toothbrush Bristle Flaring on plaque control efficacy of toothbrush.

MATERIALS AND METHODS: Thirty six subjects were randomly selected and underwent complete oral prophylaxis 10 days prior to the Baseline plaque recording. All subjects were provided with new similar toothbrushes and were divided into two groups. New Brush Group changed toothbrush every month and Old month Group used single toothbrush for the whole period of the study. Both groups were assessed for plaque accumulation every month using Turesky et al, (1970) modification of the Quigley and Hein (1962) plaque index. Toothbrush head was photographed and assessed by measuring the brushing surface area on standardized photographs using National Institutes of Health Image Analysis Program (USA).

RESULTS: Both groups showed similar plaque scores at the $40^{\text {th }}$ day; progressive increase in the plaque scores in group without changing the toothbrush were recorded at the $70^{\text {th }}$ and $100^{\text {th }}$ days. As toothbrush flaring increased, the plaque scores also increased in the Old Brush Group. Highest plaque accumulation was recorded in Mandibular Lingual aspects in Old Brush Group.

CONCLUSION: Progressive increase was seen in the plaque scores with increase in toothbrush bristle flaring.

KEYWORDS: Toothbrush, Efficacy of Toothbrush, Bristle Flaring, Plaque Removal
\end{abstract}

DOI: http://dx.doi.org/10.4314/ejhs.v23i3.8

\section{INTRODUCTION}

Oral hygiene measures have been practiced by almost every population and culture around the world since the distant past. Toothbrushes and dentifrices are widely used for cleaning the teeth. The toothbrush was invented in China in approximately $1000 \mathrm{AD}$ and made its way to Europe in the $17^{\text {th }}$ century (1). It was the later part of that century before American dentists recommended its use. Interestingly, it was a result of an obligatory tooth-brushing protocol for
American soldiers in the Second World War, and subsequently they brought the habit back home which gave momentum for widespread use of tooth brushing (1).

It has been confirmed that the accumulation of microbial plaque on teeth and supporting tissues results in the development of gingival inflammation $(2,3,4)$, and daily removal of plaque leads to resolution of gingival inflammation in just a few days (5). Of all the oral hygiene methods available, using toothbrush with toothpaste is the most widespread one (6) and is

\footnotetext{
${ }^{1}$ Department of Public Health Dentistry Kothiwal Dental College and Research Center, Uttar Pradesh, India Corresponding Author: Pradeep S. Tnagade, Email: ptangade@rediffmail.com
} 
considered to be an important factor in the longterm maintenance of periodontal health $(7,8)$. But, despite the widespread use of toothbrushes, few published studies have investigated how often toothbrushes should be renewed $(9,10)$.

Toothbrushes are over-the-counter products and therefore no special instruction for their use or renewal is given when they are purchased. Toothbrush packaging sometimes includes manufacturer's instruction that the toothbrush should be discarded after three months. However, published scientific data to support such a hypothesis are lacking.

There is little data which suggests when a toothbrush should be replaced. Surveys that have been conducted have found out wide variations in toothbrush replacement periods, with the suggested average periods of 2, 5 to 6 months (11, $12,13)$. A previously conducted study has suggested that a worn toothbrush may be significantly less effective than a new toothbrush (10). On the contrary, other studies concluded that there is no significant difference in plaque scores were achieved by the subjects with the highest toothbrush wear in comparison to those subjects with the lowest toothbrush wear $(13,14)$. However, another study has recommended that toothbrushes be replaced frequently to ensure optimal plaque control (15).

In view of the variations in the results of previous research findings, this study was undertaken to confirm whether progressive flaring of toothbrush bristles has any detrimental effect on plaque removal efficacy of a toothbrush.

\section{MATERIAL AND METHODS}

The study was designed as a 100 day randomized, prospective, parallel controlled clinical trial. The study was completed between February 2012 and May 2012. The study protocol was approved by the Ethical Committee of Kothiwal Dental College and Research Centre. All procedures in this experiment were performed according to the ethical principles established under the Declaration of Helsinki.

The determination of the sample size was done after conducting a pilot study on six samples (each group $n=3$ ). The power of the study was $80 \%$, alpha value 0.05 and standard deviation of 4 were calculated to detect a difference in means of
2 units on the primary outcome variable using a 2sided significance level $t$-test. The estimated sample size was 36 with 18 subjects in the control group and 18 in the experimental group. The subjects used in the pilot study were not included in the main experiment to increase the homogeneity in the group.

The toothbrush used in this study was a square head; $27.0 \pm 1 \mathrm{~mm}$ in length, 4 rows of bristles, 38 tufts, $38 \pm 1$ monofilaments per tuft, height of monofilaments, $9.5 \pm 0.1 \mathrm{~mm}$, and diameter of monofilaments, $0.19 \pm 0.01 \mathrm{~mm}$. A code number was inscribed on the shank of the toothbrush for identification during photography by the examiner (B).

Out of the total of 98 subjects who volunteered to participate in the experiment, 36 were randomly selected. These included 17 male and 19 female subjects. The age group of the subjects was 19-25 years and the mean age was 22.19 (SD \pm 1.15 ). All participants were dentistry students. All subjects were given verbal and written information concerning the scope of the study and a written consent was obtained. The samples had to be without any kind of systemic disease, physical handicap and had to be with complete dentition. Teeth had to be caries-free, without restorations on buccal/lingual or palatal surfaces, and had to have a probing depth $\leq 3 \mathrm{~mm}$ on the facial and lingual-palatal surfaces. All participants had to be non-smokers and without any orthodontic or prosthetic appliances/teeth. All the participants were informed that they would be excluded if at any time during the course of the study any events which might affect the plaque accumulation occurred as oral prophylaxis, placement of a restoration, any course(s) of antibiotics, use of any mouthwash, use of dental floss and any systemic illness.

The initial examination for all the willing participants was conducted by examiner 'A'. Out of all the eligible subjects, 36 samples who were selected randomly formed a single group, named as Main Group (MG).At the initial visit (0 days) or the start of the experiment, all patients underwent complete oral prophylaxis by the same operator 'A'. At the end of the visit, new similar toothbrushes were allotted to all the subjects. Each subject received verbal instructions to use only the given toothbrushes and the toothpaste which they had been using before the experiment. Subjects 
were advised to brush twice daily using the technique they preferred and no instruction was given regarding brushing time.

The first visit for plaque recording i.e., baseline recording was done after 10 days from the day of competition of oral prophylaxis and allotment of new toothbrushes. Examination was performed in the Clinic of the Department of Public Health Dentistry under artificial illumination using sterilized couth mirror, tweezers, and Shepherd's Crook Explorer. Plaque was disclosed by making the subjects rinse with erythrosine solution and recorded using the Turesky et al, (1970) modification of the Quigley and Hein (1962) plaque index. Plaque was recorded on the facial and lingual-palatal surfaces of all the teeth except the third molars.

All subjects were recalled after 30 days from baseline (at $40^{\text {th }}$ day). During this visit, prior to the plaque assessment, the toothbrushes were collected from all the subjects by examiner ' $\mathrm{B}$ ' in the absence of the other examiner ' $A$ '. At the same time, the subjects were divided into two groups with a simple randomization procedure by examiner ' $\mathrm{B}$ ' without their knowledge. The groups were named as New Brush Group (NBG) and Old Brush Group (OBG). NBG used the toothbrush for 30 days only. New toothbrushes were provided to them on the subsequent $30^{\text {th }}$ day visits after plaque assessment. The remaining subjects formed OBG and were instructed to brush with the toothbrush provided on the $10^{\text {th }}$ day for the whole period of the study. Plaque recording was done in a similar way as in the previous visit by examiner ' $A$ '. Standardized photographs of each toothbrush head were obtained in the visit for analysis of brushing surface area on the $40^{\text {th }}$ day.

All subjects were evaluated blindly by examiner ' $A$ ' at the end of the $40^{\text {th }}, 70^{\text {th }}$ and $100^{\text {th }}$ days from the start of the experiment. The new toothbrushes were provided by examiner ' $\mathrm{B}$ ' at these visits to the subjects in New Brush Group. Replacement of toothbrushes for subjects in the NBG at all visits was done in a similar manner as utilized on the $40^{\text {th }}$ day.

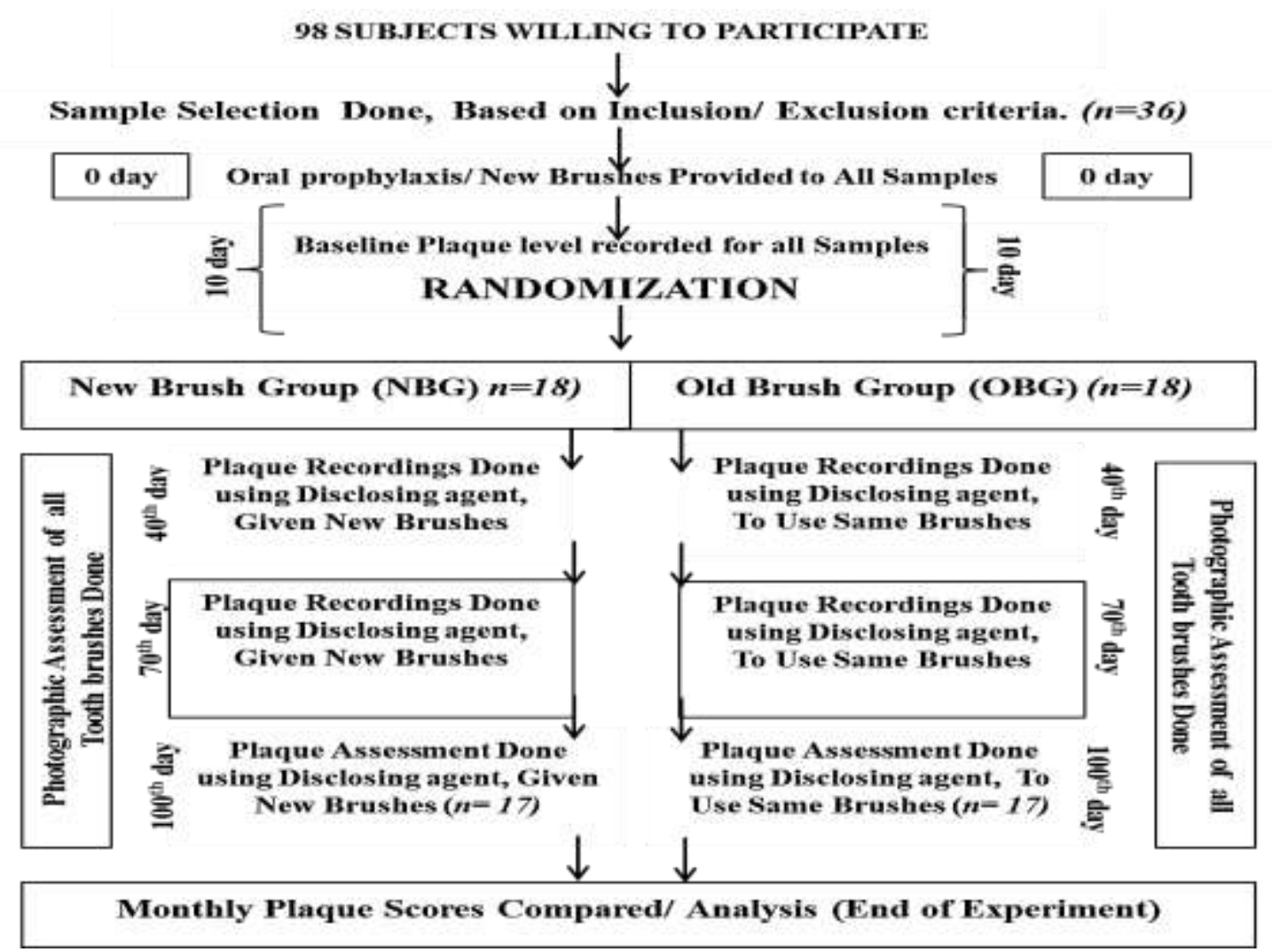

Figure1: Flow chart presenting schematic diagram of the methodology 
Toothbrush bristle flaring was assessed by measuring the brushing surface area. Standardized HD photographs of each toothbrush head were obtained during all the visits. The outline of the brushing surface area was marked and traced digitally using the Adobe Photoshop CS software. Triplicate tracings were done and images were manipulated for image quality using the Adobe Photoshop CS (Adobe Inc, USA) software package on a Microsoft Windows 7 Microcomputer (Dell Inc, India); to standardize measurements, all images were assessed in grayscale using only two colors: black and white(Figure 2); images were also adjusted to the same levels of brightness and contrast. The resultant JPEG (Joint Photographic Experts Group) images were analyzed using the NIH Image Analysis Program (National Institutes of Health, USA).This program analyzed the number of pixels within a JPEG file to enable calculation of the area within each of the tracings. Tracing procedure was done by preparing 10 tracings of each of the toothbrush heads. The mean area $( \pm \mathrm{SD})$ for each brushing surface area was then calculated. Reproducibility of image analysis was determined by performing the procedures 5 times for each of the two tracings (old used brush and a brand new brush) and by obtaining the means $( \pm$ SDs).

Participation: All plaque scoring was performed by the single examiner ' $A$ ' who was unaware of the grouping of the subjects. The examiner was calibrated at the Department of Public Health Dentistry, Kothiwal Dental College and Research Centre, in order to limit the intra-examiner variability. Intra-examiner variability was assessed by rescoring five of the participants selected randomly at each examination. The results so obtained were subjected to Kappa Statistics. The agreement for all the assessments was within the range of $85 \%$ to $95 \%$.

Toothbrushes were collected from all the subjects by examiner ' $\mathrm{B}$ ' at all the visits. The process of randomization of the subjects was also carried out by the examiner ' $\mathrm{B}$ '.

Data Processing: The data were analyzed using the patient as a unit. The primary analysis included all patients who attended the final examination. Data were entered into an Excel Sheet database (MS Office Excel 2000; Microsoft
Corporation, Redmond, WA, USA). The Data was analyzed using SPSS Statistics 19.0.

The significance of differences within the groups (over the course of the study) was sought using Mann Whitney U tests, and among groups (at each time point) using Wilcoxon matched pairs test by ranks.

\section{RESULTS}

Out of the total of 36 samples, only 34 completed the full term of the study. One subject was excluded for not using the given brush, while the other did not complete the study due to reasons not related to the experiment. The tabulation and data analysis were done for the remaining 34 participants. The New Brush Group (NBG) consisted of 8 males and 9 Females, while the Old Brush Group (OBG) had 7 Males and 10 Females.

Table 1 shows the comparison of New Brush Group and Old Brush Group with respect to total plaque scores at baseline, $40^{\text {th }}$ day, $70^{\text {th }}$ day and $100^{\text {th }}$ day from the start of experiment. Increase in the plaque scores from baseline to $40^{\text {th }}$ day was seen. Comparison of the plaque scores on the $70^{\text {th }}$ day between the two groups was statistically significant ( $\mathrm{p}<0.0008)$ and plaque tended to increase more till the $100^{\text {th }}$ day. The median plaque score difference on the $100^{\text {th }}$ day between the two groups was highly significant $(\mathrm{p} \leq 0.0002)$. Moreover, difference in the plaque scores from baseline to the $100^{\text {th }}$ day between the two groups was also found to be statistically significant $(\mathrm{p}=0.0001)$.

Regarding toothbrush wear, no significant difference was seen from baseline to $40^{\text {th }}$ day in the toothbrush surface area between the groups. However, a significant increase in the percent tooth brushing surface area in OBG was registered from the $10^{\text {th }}$ day to the $70^{\text {th }}$ day which was significantly different from NBG $(p \leq 0.0288)$, and for the $10^{\text {th }}$ day to the $100^{\text {th }}$ day $(\mathrm{p} \leq 0.0003)$ as shown in Table 1. Average tooth brush surface area increase seen at $100^{\text {th }}$ day in OBG was 12.80 $\%$ from baseline whereas in the NGB it remained almost constant in all the visits (4.48 and 3.75).

Various entanglement styles and splaying of toothbrush bristles were observed in subjects of OBG (Figure 2). Significant difference in the percentage toothbrush surface area $(p=0.0007)$ 
from baseline to $100^{\text {th }}$ day in between the two groups was also recorded.

Table 1: Comparison of new brush group (NBG) and old brush group (OBG) with respect to total plaque scores and \%Brushing Surface Areas Increase at all-time points.

\begin{tabular}{|c|c|c|c|c|c|c|c|}
\hline \multirow[b]{2}{*}{$\begin{array}{l}\text { Time } \\
\text { point }\end{array}$} & \multirow[b]{2}{*}{ Group } & \multicolumn{3}{|c|}{ Plaque } & \multicolumn{3}{|c|}{$\begin{array}{c}\% \text { Toothbrush } \\
\text { Surface Area Increase }\end{array}$} \\
\hline & & Median & $\begin{array}{c}\text { Inter- } \\
\text { quartile } \\
\text { range } \\
(x U-x L)\end{array}$ & P-value & Median & $\begin{array}{c}\text { Inter- } \\
\text { quartile } \\
\text { range } \\
(x U-x L)\end{array}$ & p-value \\
\hline \multirow{2}{*}{$40^{\text {th }}$ Day } & New brush group & 1.25 & 0.33 & \multirow{2}{*}{0.7774} & 4.32 & 4.22 & \multirow{2}{*}{0.9399} \\
\hline & Old brush group & 1.18 & 0.25 & & 3.81 & 4.47 & \\
\hline \multirow{2}{*}{$70^{\text {th }}$ Day } & New brush group & 1.12 & 0.29 & \multirow{2}{*}{$0.0008^{*}$} & 4.48 & 4.06 & \multirow{2}{*}{$0.0288 *$} \\
\hline & Old brush group & 1.42 & 0.24 & & 8.30 & 8.56 & \\
\hline \multirow{2}{*}{$100^{\text {th }}$ Day } & New brush group & 1.26 & 0.23 & \multirow{2}{*}{$0.0002 *$} & 3.75 & 4.51 & \multirow{2}{*}{$0.0003 *$} \\
\hline & Old brush group & 1.81 & 0.41 & & 12.80 & 9.16 & \\
\hline \multicolumn{2}{|c|}{ Baseline to $100^{\text {th }}$ day } & \multicolumn{3}{|c|}{$p=0.0001^{*}$} & \multicolumn{3}{|c|}{$p=0.0007^{*}$} \\
\hline
\end{tabular}

*Calculated by Mann-Whitney $u$ test $p$-value significant at $p \leq 0.05$

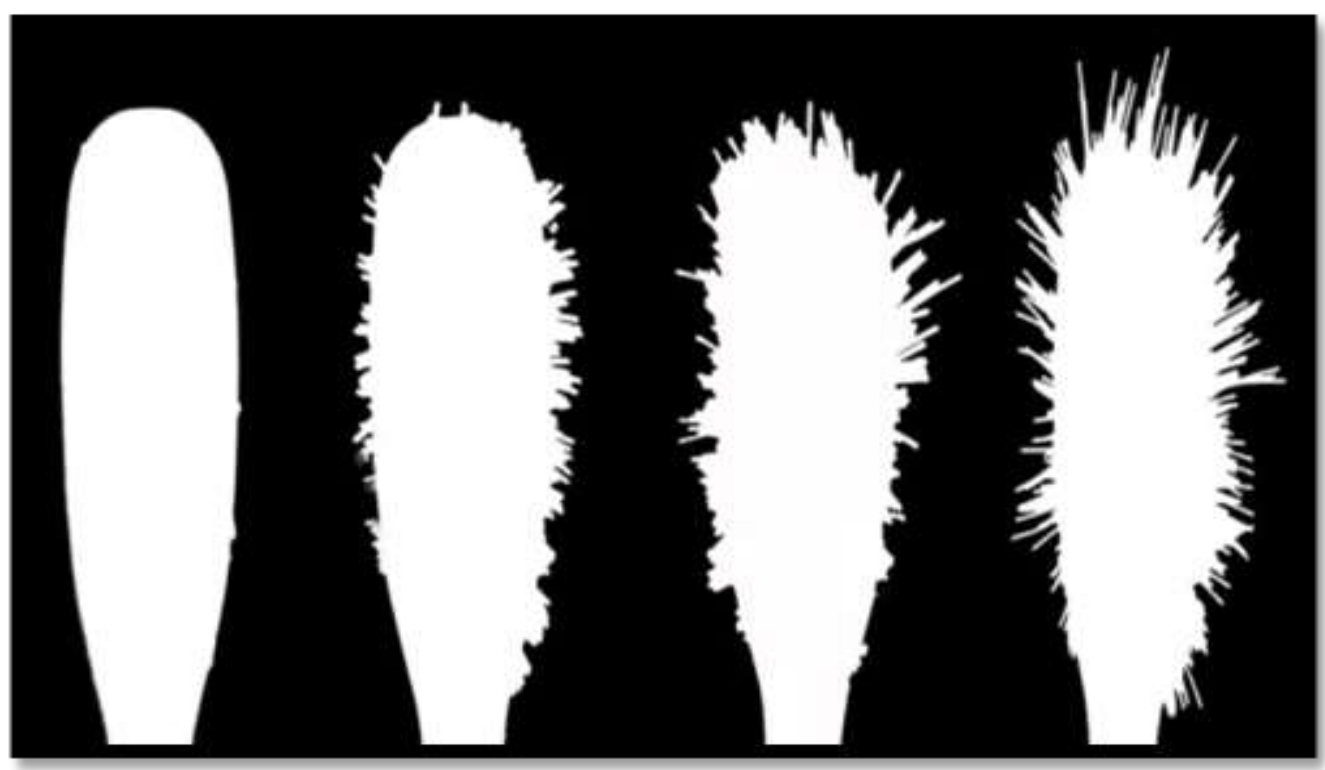

Figure 2: Various entanglement styles and splaying observed in tooth brushes 
Comparison within OBG for the $10^{\text {th }}$ day, $40^{\text {th }}$ day, $70^{\text {th }}$ day and $100^{\text {th }}$ day points with respect to total plaque scores in OBG is shown in Table 2. Plaque scores for OBG revealed a significant difference within the group and when compared to NBG values (not shown) at all the time points. Within the OBG, the highest toothbrush surface difference was recorded between the $40^{\text {th }}$ day to the $100^{\text {th }}$ day. Plaque score in OBG showed worsening development in comparison to the recordings at all-time points when compared to scores at baseline $\left(10^{\text {th }}\right.$ day $)$.

Table 2: Comparison of plaque score within Old Brush Group from Baseline $10^{\text {th }}, 40^{\text {th }}$ and $100^{\text {th }}$ day time points.

\begin{tabular}{llll} 
Time point & Median & Interquartile range $(x U-x L)$ & P-value \\
\hline Baseline & 0.74 & 0.37 & $0.0005^{*}$ \\
$40^{\text {th }}$ Day & 1.18 & 0.25 & \\
Baseline & 0.74 & 0.37 & $0.0003^{*}$ \\
$70^{\text {th }}$ Day & 1.42 & 0.24 & $0.00024^{*}$ \\
Baseline & 0.74 & 0.37 & \\
$100^{\text {th }}$ Day & 1.81 & 0.41 & $0.00029^{*}$ \\
$40^{\text {th }}$ Day & 1.18 & 0.25 & \\
$70^{\text {th }}$ Day & 1.42 & 0.24 & $0.0004^{*}$ \\
$40^{\text {th }}$ Day & 1.18 & 0.25 & \\
$100^{\text {th }}$ Day & 1.81 & 0.41 & $0.0005^{*}$ \\
$70^{\text {th }}$ Day & 1.42 & 0.24 & \\
$100^{\text {th }}$ Day & 1.81 & 0.41 & \\
\hline
\end{tabular}

* Calculated by Wilcoxon Matched Pairs test by ranks, $p$-value indicates significance at all-time points. $(p \leq 0.05)$

In both the groups Buccal/Labial and Lingual/Palatal surface plaque scores for both Mandibular and Maxillary arches were separately averaged for all teeth and compared (Table 3). No significant difference was found in the plaque scores on the $40^{\text {th }}$ day in maxillary and mandibular Buccal/labial and Palatal/Lingual between the groups. However, significant results were obtained when the maxillary palatal plaque scores were compared for both the groups on the $70^{\text {th }}$ day $(\mathrm{p} \leq$ 0.0017). Mandibular Lingual aspects also showed statistically significant results $(\mathrm{p} \leq 0.0002)$ when compared between the two groups on the $70^{\text {th }}$ day. On the $100^{\text {th }}$ day subjects in OBG presented significantly higher plaque scores in maxillary palatal aspect as compared to the plaque score of NBG recorded at same time point $(\mathrm{p}=0.0001)$. Highest plaque scores were recorded on the mandibular lingual aspects on OBG on the $100^{\text {th }}$ day against similar aspect in NBG $(p=0.0001)$.

\section{DISCUSSION}

Regular removal of plaque from all tooth surfaces is important and the manual toothbrush is the principal device for home care plaque removal (16). Of toothbrush components, the most extensively studied is the bristle design which contributes to the plaque removal efficacy of the toothbrush (17).

The findings of the present study suggest that the ability of a toothbrush in removing plaque is much related to factors like bristle flaring or tapering of the toothbrush bristles. It is obvious that as brushes are used, the bristles become splayed and this in turn increases in the brushing surface area. As observed in the present study, the plaque scores for both groups changed from the baseline and were approximately leveled on the $40^{\text {th }}$ day, on the $70^{\text {th }}$ day plaque scores exhibited increase in $\mathrm{OBG}$ and the difference in plaque score between the two groups was significant ( $\mathrm{p} \leq$ 0.0008 ). Furthermore, at the end of the $100^{\text {th }}$ day, there was significantly more plaque in $\mathrm{OBG}$ than in NBG $(p=0.0002)$. The probable cause for the increase in plaque scores is that, 
Table 3: Comparison of new brush group and old brush group with respect to plaque scores at $40^{\text {th }}$ day, $70^{\text {th }}$ day and $100^{\text {th }}$ day on buccal, palatal/ lingual aspects of maxillary and mandibular arches.

\begin{tabular}{|c|c|c|c|c|c|}
\hline Time point & Sides & Group & Median & U-value & P-value \\
\hline \multirow{8}{*}{$40^{\text {th }}$ day } & \multirow{2}{*}{ Maxillary Buccal } & New brush group & 1.04 & \multirow{2}{*}{104.50} & \multirow{2}{*}{0.3758} \\
\hline & & Old brush group & 1.00 & & \\
\hline & \multirow{2}{*}{ Maxillary Palatal } & New brush group & 1.14 & \multirow{2}{*}{125.00} & \multirow{2}{*}{0.9100} \\
\hline & & Old brush group & 1.29 & & \\
\hline & \multirow{2}{*}{ Mandibular Buccal } & New brush group & 1.14 & \multirow{2}{*}{121.00} & \multirow{2}{*}{0.7919} \\
\hline & & Old brush group & 1.14 & & \\
\hline & \multirow{2}{*}{ Mandibular Lingual } & New brush group & 1.36 & \multirow{2}{*}{119.50} & \multirow{2}{*}{0.7487} \\
\hline & & Old brush group & 1.43 & & \\
\hline \multirow{8}{*}{$70^{\text {th }}$ day } & \multirow{2}{*}{ Maxillary Buccal } & New brush group & 1.14 & \multirow{2}{*}{114.00} & \multirow{2}{*}{0.5977} \\
\hline & & Old brush group & 1.21 & & \\
\hline & \multirow{2}{*}{ Maxillary Palatal } & New brush group & 1.14 & \multirow{2}{*}{44.50} & \multirow{2}{*}{$0.0017 *$} \\
\hline & & Old brush group & 1.75 & & \\
\hline & \multirow{2}{*}{ Mandibular Buccal } & New brush group & 1.14 & \multirow{2}{*}{111.50} & \multirow{2}{*}{0.5340} \\
\hline & & Old brush group & 1.21 & & \\
\hline & \multirow{2}{*}{ Mandibular Lingual } & New brush group & 1.29 & \multirow{2}{*}{30.00} & \multirow{2}{*}{$0.0002 *$} \\
\hline & & Old brush group & 1.68 & & \\
\hline \multirow{8}{*}{$100^{\text {th }}$ day } & \multirow[b]{2}{*}{ Maxillary Buccal } & New brush group & 1.29 & \multirow[b]{2}{*}{84.50} & \multirow{2}{*}{0.1011} \\
\hline & & Old brush group & 1.36 & & \\
\hline & \multirow{2}{*}{ Maxillary Buccal } & New brush group & 1.29 & \multirow{2}{*}{15.50} & \multirow{2}{*}{$0.0001 *$} \\
\hline & & Old brush group & 1.79 & & \\
\hline & \multirow{2}{*}{ Mandibular Buccal } & New brush group & 1.36 & 8300 & \\
\hline & & Old brush group & 1.54 & 83.00 & 0.0899 \\
\hline & Mandibular Lingual & New brush group & 1.36 & 2.00 & $0.0001 *$ \\
\hline & & Old brush group & 2.00 & & \\
\hline
\end{tabular}

* Calculated by Mann-Whitney $u$ test, $p$-value significant at $p \leq 0.05$.

as the used brushes became worn because of bristle flaring their capability to remove plaque decreased. The results are in agreement with the findings of previous studies which indicated that bristle wear of toothbrush may impede the effectiveness of plaque removal $(14,18)$. Similar findings have been reported which state that brushes in good condition remove plaque more between the subjects who used same brush for 10 weeks and the subjects who changed brushes every 2 weeks $(15,21,22)$.

"Hawthorne effect" in the present study can be ruled out as it could have affected both the groups; however, plaque scores showed worsening condition in $\mathrm{OBG}$, or remained almost constant in the NBG which is suggestive of the fact that the subjects had not done anything additional to improve their plaque scores. It has also been detected that oral hygiene may improve during a effectively, while those brushes in fair or poor condition were ineffective in plaque removal (19). Previous studies also indicated that the mean values of the plaque and gingivitis increase in groups who did not change their toothbrushes in the $2^{\text {nd }}$ and the $3^{\text {rd }}$ months (20). Furthermore, similar results were demonstrated earlier when plaque was compared

clinical trial as a result of anticipation of oral examinations. However, in the present study, during all of the examinations, plaque scores were not disclosed to the participants so that participants remained unaware of their plaque scores till the end of the study.

In the present study, the percentage of toothbrush surface area showed significant difference $(\mathrm{p} \leq 0.003)$ from baseline to the $100^{\text {th }}$ day in OBG. Similar results were found previously where the mean surface area of toothbrush showed 
increase by $10.0 \%$ at the end of the $9^{\text {th }}$ week (14). Various studies also reported that brushes which had been used continuously for 6 weeks revealed a degree of wear significantly greater than brushes used for only a fortnight $(15,23)$. The amount of toothbrush wear which was registered in the form of tooth brush bristle flaring demonstrated by the 3-month-old toothbrushes in the present study varied widely. The variation in the toothbrush surface area increase could have been caused by many factors like brushing force and technique. Other factors such as individuals' variations in arch shape and size, tooth size and inclination, cusp and incisal edge form and sharpness and inter-dental embrasure sizes could also be contributing factors. Habits such as chewing the brush head while brushing could also be a factor. The variation in the amount of wear shown by toothbrushes during use was reported previously in many studies $(11,12,13,14,18,24)$. An earlier study also demonstrated that people who brush with the highest forces produced more toothbrush wear (25).

Significant differences between plaque accumulations were also recorded on the $100^{\text {th }}$ day between the groups and within both arches as well as between different aspects in OBG. The present study illustrated that there was increased plaque accumulation on the mandibular lingual aspects and maxillary palatal aspects. The results revealed that an old brush removed approximately similar amount of plaque from mandibular and maxillary buccal aspects of teeth on the $70^{\text {th }}$ day as a new one did. However, on the $100^{\text {th }}$ day, the differences recorded were pronounced on the mandibular lingual and maxillary palatal aspects between the groups as well as within both arches in OBG. The possible reason for this can be that plaque removal effectiveness of a toothbrush with flared bristles is less which might be because of the fact that these surfaces become more difficult to reach with flared bristles. Similar outcomes were stated previously that the buccal areas are effectively cleaned by old toothbrushes which are followed by the Lingual and Mesial-Distal areas (18). Furthermore, it was also reported that toothbrush design has an impact on tooth-brushing efficacy, particularly in areas that have been more difficult to clean, such as the lingual, interproximal, and posterior surfaces (26).
In the present study, the most possible reason for the higher plaque scores for the mandibular arches than maxillary arches could be that there was more plaque formation on mandibular region thus the amount of residual plaque on the mandibular region after brushing by a toothbrush with flared bristles increased with every visit, which can be due to the cumulative effect of plaque with time. Experiments assessing the patterns of de-novo plaque formation in various parts of the human dentition during a period of no oral hygiene have reported that more plaque is formed in the mandibular than in the maxillary dentition and this difference remains more pronounced at lingual/palatal surfaces (27). A similar finding was reported by a previous study which stated that significantly more plaque persisted on lingual and palatal surfaces when compared with facial surfaces of teeth (14).

It is evident from the present study that progressive toothbrush wear in the form of toothbrush bristle flaring has a definite and immense disadvantageous effect upon a brush's ability to remove plaque. The most possible reason for this can be that as a toothbrush flares, the design of toothbrush bristles changes from conventional design, thereby the efficacy of a toothbrush is degraded.

In summary, the progressive increase in the plaque accumulation which was registered as the duration of tooth brush usage increased in OBG could be suggestive of the fact that bristles that show widening, twisting, spreading, bending, tapering or show matting of the filaments which are recognized as indicators of a worn-out toothbrush $(23,24)$ decreasing the functional ability of a toothbrush. Thus, it can be concluded from the findings of this study that toothbrushes which have been used for a period of three months are unable to remove plaque efficiently.

It is recommended that as standards for toothbrushes are developed, the rate of loss of effectiveness of a brush because of bristle flaring should be considered as an important factor for replacing a toothbrush since a brush loses its effectiveness with use. We recommend that the users should be given a picture of a typical worn brush head showing bristle flaring, and they should also be advised to discard their toothbrush when it matches the picture. 


\section{REFERENCES}

1. Penick C. Power toothbrushes: a critical review. Int J Dent Hyg. 2004;2(1):40-4.

2. Theilade J, Lobene RR, Mandel ID, Hazen S. What is the relationship between bacterial plaque and calculus formation? Periodontal Abstr. 1967;15(2):53-6.

3. Breuer MM, Cosgrove RS. The relationship between gingivitis and plaque levels. $J$ Periodontol. $1989 ; 60(4): 172-5$.

4. Holt SC, Ebersole J, Felton J, Brunsvold M, Kornman KS. Implantation of Bacteriodesgingivalis in non-human primates progression of periodontitis. Science. 1988 Jan 1;239(4835):55-7.

5. Loef H, Theilade E, Jensen SB. Experimental gingivitis in man. J Periodontol. 1965;36:17787.

6. Axelsson P. Mechanical plaque control. In: Lang NP \&Karring T eds. Proceedings of the 151 European Workshop on Periodontology. London: Quintessence Publishing, 1994; 219243.

7. Axelsson P. Needs-related plaque control measures based on risk prediction. In: Lang, N., Attstrom, R. \&Loe, H. (eds): Proceedings of the European Workshop on Mechanical Plaque Control, Chicago: Quintessence Publishing, 1998; 190-247.

8. Manly RS. A structureless recurrent deposit on teeth. Jour Dental Res. 1943; 22(6): 479486.

9. Abraham NJ, Cirincione UK, Glass RT. Dentists and dental hygienists attitudes toward toothbrush replacement and maintenance. ClinPrev Dent. 1990;12(5):28-33.

10. Daly C, Marshall R. Attitudes to toothbrush renewal: A survey of Australian periodontists and dental hygienists. Periodontol. 1996;17:118-121.

11. McKendrick AJ, McHugh WD, Barbenel LM. Toothbrush age and wear. An analysis. $\mathrm{Br}$ Dent J. 1971; 130(2):66-8.

12. Bergstrom J. Wear and hygiene status of toothbrushes in relation to some social background factors. Sven TandlakTidskr. 1973; 66(4):383-91.

13. Dean DH, Beeson LD, Cannon DF, Plunkett CB. Condition of toothbrushes in use:
Correlation with behavioral and socioeconomic factors.ClinPrev Dent. 1992;14(1):14-8.

14. Daly CG, Chapple CC, Cameron AC. Effect of toothbrush wear on plaque control. $J$ ClinPeriodontol. 1996 Jan; 23(1):45-9.

15. Glaze, P. \&Wade, B. Toothbrushes age and wear as relates to plaque control. $J$ ClinPeriodontol. 1986 Jan;13(1):52-6.

16. Cugini M, Thompson M, Warren PR. Correlations between two plaque indices in assessment of toothbrush effectiveness. $J$ Contemp Dent Pract. 2006;7(5):1-9.

17. Hotta M, Yoshida T, Sekine I, Imada S, Sano A. Evaluation of tapered-end toothbrushes regarding subgingival access efficacy. $J$ Clin Dent. 1997;8(6):156-8.

18. Kreifeldt J, Hill P \&Calisti L. A systematic study of the plaque removing efficiency of worn toothbrushes. J Dent Res. 1980;59(12):2047-55.

19. Robertson NAE. \& Wade AB. Effect of filament diameter and dentistry in toothbrushes. Journal of Periodontal Research. 1972, Vol. 7 Issue 4, p346-350. 6p.

20. AL-Naimi RJ. Evaluation of Toothbrush Wear on Toothbrushing Efficiency. Al-Rafidain Dent J. 2009; 9 (1):51-56.

21. Warren PR, Jacobs LDS, Low M, Chater B and King D. A clinical investigation in to the effect of toothbrush wears on efficacy. J Clin Dent. 2002; 13(3):119-24.

22. Conforti NJ, Cordero RE, Liebman J, Bowman JP, Putt MS, Kuebler DS, Davidson KR, Cugini M, Warren PR. An investigation in to the effect of three months clinical wear on toothbrush efficacy: results from two independent studies. J Clin Dent. 2003; 14(2):29-33.

23. Galgut PN. The influence of toothbrush wear on the variables of plaque and gingivitis in clinical trials. J Dent Hyg. 2001;75(2):150-5.

24. Hegde PP, Kumar A, Ankola AV. Toothbrush age, wear, and plaque control. Indian J Dent Res. 2005 Apr-Jun;16(2):61-4.

25. Pugh B. Toothbrush wear, brushing forces and cleaning performances. J SocCosmet Chem. 1978;19:423-431.

26. Terezhalmy GT, Bsoul SA, Bartizek RD, Biesbrock AR. Plaque removal efficacy of a prototype manual toothbrush versus an ADA 
Reference Manual toothbrush with and without dental floss. J Contemp Dent Pract. 2005;6(3):1-13.
27. Euruichi Y, Lindhe J, Ramberg $P$ and Volpe AR: Patterns of de-novo plaque formation in the human dentition. $J$ ClinPeriodontol. 1992;19(6):423-33. 